\title{
A Lesson before Dying: Embracing Innovations for Community Engagement as a Survival Strategy for Media in Crisis.
}

\author{
Sam Chege Mwangi, \\ A.Q.Miller School of Journalism and Mass Communications, \\ Kansas State University, \\ Email: scmwangi@k-state.edu
}

\begin{abstract}
As media organizations confront an uncertain future unleashed by disruptive technologies, they are searching for ways to successfully navigate the changing information landscape. This paper argues that one way out of the present crises is for media to embrace a culture of innovation and use engaging communication technologies that are mutually beneficial to the media and to the communities they serve. The paper maps trends in media innovations and then reports on a unique innovation project that designed a new digital tool to help media re- engage their communities in new ways. The success of the project suggests that innovative tools and services that are specifically geared towards community engagement can provide a lifeline for media in crises as well as transform community news, information distribution and visualization, and impact community conversations, making new media technology a valued ally to media organizations and communities rather than a disruptive threat.
\end{abstract}

\section{Introduction}

Emerging communication technologies have disrupted the established media economic models of information production and distribution in significant ways (Dahlgren, 1996; Bratich, 2004; Shirky, 2008). The disruption has led to widespread closure of newspapers and loss of jobs. By 2008, the bottom dropped out of the newspaper industry with more than 15,000 newspaper employees losing their jobs in the U.S. The downward spiral continues unabated. According to the 2010 State of the News Media Report, advertising revenue fell $43 \%$ over the last three years. Roughly 13,500 jobs disappeared in the same 
period and newspapers entered the year 2010 devoting $\$ 1.6$ billion less annually to the news business than they did three years ago (Pew Project for Excellence in Journalism, 2010).

The new communication technologies present both opportunities and challenges. News organizations are experimenting with ways to exploit the new technologies to reinvigorate journalism and address contemporary needs (Zamith, 2008). Some scholars have discussed the potential of using new media technologies to promote civic engagement (Schultz, 1999; Rosenberry, 2005; Nip, 2006). Scholars have identified three dimensions of civic engagement that such interactive features must provide namely, connecting to the community; engaging individuals as citizens; and helping public deliberation in search of solutions (Nip, 2006). Responding to the crisis in journalism, the Knight Foundation established the News Challenge Fund in 2007 to provide competitive grants to initiatives aimed at creating digital innovations to help media organizations re-engage their communities. This paper reports on one such project that brought together journalism students from seven universities and challenged them to come up with cutting edge innovations to help media organizations re-engage their audiences. The first phase of the project ended in September 2010. The project provides an example of how the news media can embrace innovations in new technology to survive and thrive while serving community needs through community engagement.

\section{Trends in Media Innovation}

Research on media and innovation paints the picture of an industry that has not always embraced innovation as a critical part of its mission and was content with the age-old model of relying on advertising and subscription to finance its business. The disruption of that model means the media industry is not just looking for a new model, but they suddenly have to understand the concept of innovation itself. They are also under pressure to respond to the increasing sophistication of audiences who now expect to participate in the process of content creation and dissemination. Research contributions 
from a few scholars add insightful suggestions on the way that media could embrace a new paradigm shift as they negotiate the changing technology terrain.

According to Rosabeth Moss Kanter, the Ernest L. Arbuckle Professor of Business Administration at the Harvard Business School who studies innovations and leadership for change in organizations, one of the greatest irony of the technological changes now disrupting media industries is that the media are often the first to report about new technologies (as news stories) but they never seem to ask how the technology might actually affect or improve the news business (Niemann Reports, 2002). As a result, the media have tended to be slow in developing appropriate and strategic responses. Part of the reason is that journalism and innovation are often treated as two separate enterprises even though one has the potential to add value to the other. She suggests that it is important to foster a culture of organizational curiosity that brings employees together to look at technologies of the future and find ways to integrate them in the news business. She offers several critical lessons on ways the media industry could become innovative: First, there is need for the media to internalize a culture of change and innovation including hiring leaders who embrace and encourage innovation. She cites the example of Reuters, the financial news company, as an organization that was most threatened by the internet because, if people could find the information online freely, Reuters business model was doomed. But through a leadership that embraced change, Reuters was able to team up with Yahoo!, in the latter's formative days, in a strategic alliance that made both companies big brand names in the USA in a way they hadn't been. The lesson then for media companies is: "Figure out what could hurt you and then figure out how to bring that inside," (Niemann Reports, 2002, pg. 30).

Second, she says, media companies must understand that innovation involves a lot of unscripted experiments without a clear understanding of what the end product or process might look like. Companies that are successful at innovating, simply start moving, often working with multiple partners on multiple projects, but paying attention to customer feedback and improving until they find out what works. 
Third, companies that are innovative tend to be structurally flexible and are less territorial because they have created a culture of shared values across all areas. Change becomes organic and the organization simply changes without announcing they are changing.

Fourth, while innovation has centered on technology, there is need to pay attention to the economic angle as well. She advises against straying from a company's core business areas especially in response to market whims. The best innovation strategy is one that uses technology to evolve the core business, which is a more secure bet.

Fifth, innovation and experimentation must not always be measured in terms of financial returns. Experiments offer important learning lessons and "learning" should be a valued output.

Other scholars posit that information gathering and trend watching are important skills in responding to transformative change. Media publishers and journalists should therefore learn to think like innovators by developing a knack for trend watching, spotting opportunities and capitalizing on them. They suggest that those in media interested in innovation should develop a habit of looking at trends, searching for solutions to negative trends, coming up with ideas that run against current trends, and watching the competition and doing what they do better (Waitley and Tucker, 1987).

Boczkowski offers a user-centered approach to understanding innovation and argues that online journalism has created certain user expectations that innovative media organizations must strive to address. Using what he calls "distributed construction," which refers to the process of enabling users to participate in content creation and distribution, he says user participation creates a multiplicity of information flows as well as multiple rationalities. He suggests that a good way for innovative media to enable user participation is by capitalizing on the strengths of online journalism such as its immediacy, multiple representations, multimedia options, flexible delivery platforms, archival access, and nonlinear narratives. He further argues that the internet has created the closest approximation to Habermas idea of the public sphere in which citizens express 
opinion on public matters. But while innovations must continue to make the internet more widely accessible to the public, there is need to guard against its increased commercialization because commerce and corporate interests might lead to the taming of critical debate (Boczkowski, 2004).

After a seven-year longitudinal study, Greer and Mensing found that newspapers had over time embraced multimedia elements as well as interactivity and that innovations tended to happen first at large papers, then medium ones before finding their way to smaller papers. The authors attributed the evolution of web-based news to interaction between news organizations and their audiences. "The sites are responding to the increased sophistication of online readers, providing more multimedia features, deeper content, and more frequent updates." (Greer and Mensing, 2006, p. 30). They observed that the tightening connection between the receiver and the communicator has led to a shift in journalism from a product to a service model of journalism. In a related article, Deuze observes that the changing patterns of interaction between readers and news content have led to the emergence of monitorial and dialogic journalism (Deuze, 2003). He defined three characteristics of online publishing that must guide both journalists and media innovators------hypertextuality, interactivity, and multimedility. The application of each of these elements has a consequence for the type of journalism produced on the web as well as the news culture itself:

"The online journalist has to make decisions as to which media format or formats best convey a certain story (multimediality), consider options for the public to respond, interact or even customize certain stories (interactivity), and think about ways to connect the story to other stories, archives, resources and so forth through hyperlinks (hypertextuality)" (Deuze 2003, pg. 206)

Tremayne et al (2007) argue that the technological changes have produced what they call "a dynamic journalism content" which changes hour-by-hour on newspaper Web sites. These changes include the addition or subtraction of stories, altering headlines, changing 
or adding photos, and other multimedia elements. This has consequences for journalists at least in three areas. First, the age old practice of publishing once a day or weekly has been replaced by a new model that requires publishing on a continuous basis and newsrooms have to find a way to address that. Second, journalists are expected to exploit the advantages of the new medium through the use of video, audio and animated graphics. Third, the new medium affords users the opportunity for greater activity and involvement and the corresponding ability of newspapers to monitor that activity, harness it, and respond to it. The authors make the interesting observation that innovations in journalism appear to be driven by consumers and not necessarily the media organizations themselves.

Other scholars have suggested that media innovation must pay close attention to mobile phones as the likely future of media. The convergence of mobile phones and multimedia now enables information processing through audio, video, text, graphics and animation. As a multimedia tool, the mobile phone is portable, constantly connected, and personal, which has also led to a more individualized news consumption pattern (Westlund, 2008).

Some scholars have addressed innovation by looking at the promising capabilities of computational journalism that would equip journalists with better reporting tools. A report from the Center for Media and Democracy at Duke University identifies four target areas for helpful innovation: more efficient data-analysis tools to help reporters discover patterns; open source software reporting tools to spot anomalies in information; a watchdog role for readers; and more collaborative research with professionals such as social scientists and medical personnel, among others (USA Today, 2009).

Sagan and Leighton point out that the fastest growing medium on the internet is video and it is likely to have the biggest impact on online news. This might mean coming up with more innovative ways of harnessing its potential (Sagan and Leighton, 2010). 
A recent report by Innovation Media Consulting, a global consultancy that specializes in news media, collates recent innovations that are likely to further re-shape online publishing (Campaign, 2010). Among these is Augmented Reality, which can offer a 360 degree view of live visual content whose augmented elements are generated by computer technology:

Somewhere in the London suburbs, a young man gets home from a night out. Before he goes to bed, he grabs his favorite magazine and flips to a page with a beautiful actress on it. He turns the page to face his webcam, and she pops up on screen giggling and telling him a dirty joke. (Campaign, 2010, pg.14)

The potential for Augmented Reality in adding value to news content and advertising through engagement, interactivity, play and immersion is immense once the innovation goes mainstream.

A new and comprehensive report released by the International News Marketing Association surveyed news media organizations, especially in Europe, Asia and the USA, to find out how they were repositioning themselves in response to what it called "the technology-driven seismic shift," (Wilkinson, 2010). The report yields several useful and surprising insights on innovation trends as well as challenges in newsrooms around the world:

While most of the literature on media and innovation focuses on the urgency of serving audience needs on continually evolving platforms, the connection between innovation and business is not always made. It therefore might come as a surprise to learn from the report that some newspapers that draw most of their revenue from print advertising have decided to be deliberately slow in embracing online innovations so as not to close the window on newspapers at a time when revenue from online platforms is not enough to sustain their operations. 
The report also documents instances where innovative thinking has resulted in new and unconventional value propositions. For example, while current trends emphasize the value of the digital content, Minnesota's Star Tribune has instead decided that the real value of its products is in its print content. Therefore it will reserve its best journalism of deeply reported stories, beautiful narratives and investigative projects for the print edition where it gets its most advertising value, while reserving its online platform for breaking news and less weighty stories. Newsweek has followed a similar trend by reserving original, provocative, and unique reporting for its print edition. The decisions in both cases were driven largely by the need to find an acceptable model that would address the financial needs of the media outlets and reward their valued audience with quality journalism, even while maintaining some form of web presence.

Other news organizations have encountered a problem online that they had not anticipated in the form of news aggregators that collect headlines and distribute them widely. On the face of it, the practice looks like good business for the news media since their content is able to reach a wider audience. But it becomes hard to sell such an amorphous audience to advertisers thus resulting in a loss of revenue. It also dilutes the brand names of such news organizations. Furthermore, while most media organizations that have a website have seen an increase in audience size, some of that audience is brought in by search engines and leaves after a few minutes, again making it hard to target advertising.

The new media technologies have also created another trend where huge companies with a national audience such as ESPN have started local operations that are cannibalizing the advertising market. The report suggests that one possible solution is for local media to adopt an innovative approach by taking advantage of their local roots and audience loyalty in their communities to offer hyper local content that creates deep loyalty and engagement that serves tightly knit audiences that are equally valuable to advertisers. 
The report notes the need for culture differentiation in leveraging the different platforms. For example Schibsted, a large media company in Norway with a presence in television, newspaper, online, mobile, book and film industries has created a deliberate disconnection between these different platforms to encourage full development of each brand in terms of audience, content and sales force devoted exclusively to each brand. The company is profitable and generates U.S.\$1.2 billion annually. Instead of leveraging the synergistic opportunities that such cross ownership presents, Schibsted is more than happy to develop each brand separately around its own culture. The success of this model challenges conventional thinking that emphasizes convergence and pays little attention to the cultural orientation that each platform fosters.

Norway offers a second lesson of innovative thinking through the popular classifieds portal, Finn, built around a model of burrowing into ever deeper but exhaustive advertising sub-categories that give it a presence in every conceivable niche market. The portal is a joint project of several Norwegian media companies who were looking for a reliable way to finance their separate news business. And while such an experiment might appear to undermine the newspapers own individual classifieds businesses, it is a successful experiment that leverages the power of several brand names into one platform to generate over $\$ 100$ million in revenue and close to a $40 \%$ profit margin. It also proves that new media technologies can be a boon to news media through deployment of new and highly focused metrics.

The report notes that innovation goes beyond adopting the latest technologies and there is a need to continue searching for sustainable economic models even as the debate continues on whether companies should charge for their online content or give it away for free. While this question is far from settled, there may be a lesson to learn from the way the music industry has responded to disruptive technologies. While the music is free on several sites, it is never freely distributed. Instead, users have to go to specific sites for certain music where they are then targeted with ads. The report also argues that one can build an economic model around paid content as long as it meets one of three criteria: offers unique content that users cannot get elsewhere; provides fast content that benefits 
users who get it before anyone else; and provides content that brings users closer to groups they value. This calls for relentless differentiation on the part of the news organization in order to stand out from the pack.

As media organizations strive to respond to today's changes, it is important to anticipate and plan for the technological changes of tomorrow which may include more data-driven rather than narrative-based products, non-proprietary products, smaller and smarter gadgets such as mobile phones and e-readers, as well as smart informatics for navigation, search, archiving, targeting, and predictive accuracy. Each of these innovations will have an impact on journalism as a profession and its products and will require an appropriate response from news organizations. Therefore news organizations have no choice but to embrace a culture of innovation for their very own survival and to thrive in the constantly changing information environment.

\section{Theoretical Framework}

Two theoretical models provide the foundation for understanding the attitudes and responses of media workers and media organizations to the technological innovations currently impacting the news business. These theories are the diffusion of innovations theory and the disruptive technology theory. In his seminal book, Diffusion of Innovations (1964), Everett Rogers defined "diffusion of innovation" as "the process by which an innovation is communicated through certain channels over time among the members of a social system. Rogers synthesized 508 diffusion studies and developed a theory for the adoption of innovations among individuals and organizations. He identified five stages in the innovation process that organizations undergo: agenda-setting, matching, redefining/restructuring, clarifying and routinizing. (Lawson-Borders, in a subsequent study, developed a rubric for the media industry's adoption of new media technologies based on Rogers five stages: the first stage —agenda setting-was when

media companies recognized the implications of the internet and the growth of personal computers; the second stage - matching — was the resultant creation of online divisions to exploit the potential of the internet; the third stage - redefining/restructuring - was the 
dot.com bust when media organizations retrenched and reduced online resources; and the fourth stage - clarifying — was the increasing focus on convergence. Routinizing refers to the mainstreaming of the innovation when it becomes a part of the organization's structure (Lawson-Borders, 2003).

Closely related to this theoretical sketch is Clayton Christensen's disruptive technology theory that seeks to explain organization's responses to technology. In his 1995 article, Disruptive Technologies: Catching the Wave, which he co-wrote with Joseph Bower, he argued that a disruptive technology can come to dominate a market by filling a role that the old technology wasn't filling or through performance improvements until eventually replacing old market incumbents. In subsequent writings, Christensen replaced the term "disruptive technology" with "disruptive innovation" arguing that few technologies are intrinsically disruptive and that it is the business model that the technology enables that eventually creates a disruptive effect. He distinguished between low-end disruptions that cater to customers who might not be interested in the high performance valued by high end consumers, and the new markets disruptions that tend to meet needs that were previously unmet by existing organizations. For example, early desktop publishing systems could not match the performance and capabilities of high end computing systems but nevertheless catered to the specific needs of low-end consumers and eventually changed the entry cost to the publishing world and disrupted the markets for established players that were slow to respond to the emerging technology. According to this theory, technologies that damage established companies are not usually very radically new from a technological perspective. But they have two characteristics: they usually present a new set of performance attributes and such attributes are not initially valued by the established companies. The new performance attributes improve at such a high rate that the technology can later invade established markets. For example although personal computers did not meet the performance of mainstream minicomputers in the 1980s, the computing power of desktop machines improved faster than the needs of minicomputer users and caught up with the computing needs of customers for Wang, Prime, Data General and Digital Equipment companies. Senior executives must be able to spot such 
technologies and develop and commercialize them in a way that protects their existing customers. He argues that since most organizations are geared towards satisfying their customers' needs, they have developed and invested in business models geared towards those customers. The processes and incentives that companies use to keep focused on their main customers work so well that they blind those companies to important new technologies in emerging markets.

Understanding the gradual diffusion of innovations and a historical perspective on disruptive technologies can help media organizations develop a well-grounded view that can guide them in developing workable models and templates for adopting innovations. The following case study provides a practical example of how the media can embrace innovation by developing digital tools that are both engaging and valuable to their audiences and re-orient themselves to take advantage of the seismic shifts in the information world.

\section{Case Study}

The Innovation Incubator Project, sponsored by the Knight Foundation under their News Challenge Initiative, was designed to create a national network of incubators through which college students would design, develop, and work with professional newsrooms to distribute new and original (digital) applications of community news. Using the creation nets model, the project would create a contemporary Petri dish that was collaborative, participatory, and dynamic, to develop original solutions to the challenges facing journalism in a digital age to help newsrooms re-engage communities.

The Creation nets model refers to a form of open innovation designed to harness the potential of distributed innovation pursued by a group of participants. Open innovation in this case is broadly defined as a paradigm that assumes that firms can and should use external ideas as they look to advance their technologies and processes (Hagel and Brown, 2006). But by their very nature, creation nets are adept at continuously innovating the process and roles to deliver the required performance and results and 
collaborate to create new knowledge to learn from one another, and to appropriate and build on one another's work. By leveraging the creativity of other participants, creation nets are a good way to generate superior results and successful innovations. While this method of innovation has been perfected by companies such as Procter and Gamble, Cisco and Eli Lily, it is not limited to for-profit corporations and Wikipedia is perhaps a good example of a loose creation net as are examples where amateur astronomers pool together hundreds of telescopes online to track celestial events. Creation nets can be formed to achieve short term or long-term objectives. In 2000 for example, P\&G, after realizing that the products coming from their own in-house innovation team were failing to meet financial expectations and share prices had fallen by more than 50 percent, decided to turn to outside help including consultants and loyal customers through a creation net that leveraged the creativity of participants. Creation nets can range from small groups to hundreds or even thousands of participants in the pursuit of distributed, collaborative and cumulative innovation.

Creation networks are often put together by an organizer who serves as a gatekeeper and defines the participation protocols and how results will be measured. While creation nets have been popularized by modern communication technologies, the first recorded creation nets are traced back to the Italian Renaissance in Piedmont and Tuscany that produced rapid innovations in techniques for producing cotton and fabrics. Creation nets tend to organize their activities into modular processes, which leaves a lot of freedom to participants to innovate their approaches in delivering the expected performance. Such process innovation is often in contrast to the established organizational approach. But in spite of such a "free" innovation process, creation nets tend to be remarkably focused in developing their action points where participants must come together and deliver outputs. Among the rewarding experiences of working in creation nets is the ability to get better faster by working with others in networks rather than working alone. Chesbrough (2005) argues that the old "closed innovation" model---vertically integrated research and development departments that develop technology in-house for the sole use of their corporate parent---is becoming obsolete in an age of mobile scientific workers, 
ubiquitous high-tech startups and a growing extra-corporate research establishment at university labs. Technology companies such as Cisco, Lucent, Intel and Microsoft do little of their own basic research and have instead pioneered a new model of "open innovation," in which companies import ideas from outside.

Participants in the Knight Foundation Innovation Incubator project were: Michigan State University, Kansas State University, Kansas University, Ithaca College, University of Nevada Las Vegas, Western Kentucky, and St. Michael's College in Vermont. The project commenced in Spring 2007 and the first phase of testing the final innovation was completed in September 2010. From the outset the project established a few rules and guidelines to govern the process. Each university recruited five students who would work under a faculty mentor to create new media innovations that could help engage communities in new ways. To ensure that the project lived up to its premise of leveraging the creative and intellectual capital of the young generation who are more likely to think outside the box, faculty mentors would not be allowed to generate any ideas. They could serve as a sounding board, probe students' ideas, challenge them and share any relevant research with them. But the origination and vetting of new ideas was solely the responsibility of students. Because this was going to be an extremely challenging, frustrating and difficult process, students who joined the project could not quit. Each university was at liberty to decide how to reward the students for participation. Some awarded credit or a stipend. Students were selected on their willingness to abide by the rules and, more importantly, it was an honor to be selected because this project would thrust them at the cutting edge of the media innovation process and they had a shot at creating the next big innovation in new media.

Disagreements on ideas and the process had to be resolved amicably, either by the students themselves or with the help of the faculty mentor. All students had to start the process by reading, Creation Nets: Harnessing the Potential of Open Innovation by John Hagel III and John Seely Brown to understand how the creation nets process works. All the teams met at Ithaca College for an orientation session designed to create a better 
understanding of the creation nets process. For an idea to be considered a winner, it had to be new, digital, and one that could be tested easily and affordably by media organizations. Students also spent time in the lab visiting select websites identified by faculty as examples of the latest media technology and learned how to research their ideas. Students had about two months to work on their projects before traveling again to Ithaca College in New York in Summer 2007 where they presented their best ideas before the other teams. The top idea would be developed further and presented at the annual Online News Association conference in November 2007 where it would be pitched to the media industry for possible adoption. The grant would cover any initial costs that the media companies would incur if they decided to adopt or test the new innovation.

Once they had understood the creation net process, each group set its own mode of operation. Some groups set up blogs where they would post their ideas and discuss and vet them. Others such as the five students from Kansas State University (mentored by this researcher) decided they would meet once a week to discuss their ideas. The Kansas State University students challenged each other to come up with five brand new ideas. They had the unenviable task of researching and crawling the web to make sure that whatever ideas they came up with were not already out on the web. While the students researched possible ideas, their mentor scoured sites that discussed media and information technology trends. Any information that could spark an idea in the students was promptly shared with the group. In their second meeting, each Kansas State University student presented five ideas. The students then whittled down the initial 25 ideas to the top five. For an idea to be included, it had to be brand new, easy to implement, usable and result in new ways of engaging the community or a section of the community. Because of the intensive nature of the process, students became heavily invested and developed a sense of ownership of the ideas they developed. Therefore there were heated discussions leading up to the selection of the top five ideas because each student felt their ideas were the best. The role of the faculty mentor became critical in making sure the selection process was as fair as possible and that disagreements did not undermine the critical need to keep the group together. The final five top ideas from Kansas State University were 
carefully discussed and vetted by the group. In the end the Kansas State University group chose to present an intuitive user centric college news site that would combine the same interactive features common among social networking sites. They called it Novus.

All the participating schools presented their projects in Ithaca, New York and voted on the project that was the most innovative, cutting edge and easy to replicate. While the initial idea was to pick just one top idea for presentation at the ONA conference, faculty mentors felt that due to the intensive nature of the process, there was need to reward more than one group. Therefore three top ideas were selected. Unfortunately, Novus was not among those selected as the participants felt that the project would require a significant amount of money to implement and newsrooms might not be willing to invest so heavily on a new idea.

The team from Kansas State University joined the project presented by Kansas University and this researcher served as the faculty mentor of the combined team. Kansas University had a simple idea that was easy to execute. Their project, known as Better Letter, was designed as an online application that could be embedded in online news stories to help the public contact public officials regarding public issues raised in news stories. The officials would respond to such letters and their responses would be delivered to the user and also be displayed on the news site. The program was tweaked to include a mapping feature so that public officials were able to identify the nature of issues coming from a particular zip code. The three final projects were presented at the ONA Conference in Toronto Canada in November 2007 where several media outlets expressed an interest in testing them on their sites.

The Kansas team partnered with the local Mercury newspaper in Manhattan, Kansas, to test the idea. The team hired the services of a professional programmer to embed the program to the site and incorporate mapping features. The name of the project was changed from Better Letter to VoxPop to capture it's intent of giving the public a voice on issues of public concern. In Spring 2008, the VoxPop project invited local leaders 
from the Manhattan City Commission, county leaders and state representatives to an official launch of the project. Following the launch, the newspaper devoted promotional space on its website to publicize the project. The first phase of testing the project ended in September 2010.

The use of VoxPop as a tool for community engagement has tended to pick up more traffic during periods of intense local political activity such as elections. For example, the program was extensively used during the recent local election coverage when the newspaper allowed readers to respond to the full text of the candidates' answers to local issues. The Mercury has recently switched to a subscription-based model that now limits access to site content to paid customers thus affecting traffic to VoxPop on a regular basis as originally intended. But according to the editor, the newspaper intends to continue using VoxPop on future interactive campaign coverage.

\section{Lessons from the Project: Discussion and Conclusion}

As media companies struggle to find a working model in the sea of technological changes, this project offers vital lessons for a struggling industry. The VoxPop project was premised on the assumption that a good digital innovation should be mutually beneficial to both the media organization and the community they serve. Voxpop was used 596 times during the period of testing. This is a remarkable number for a new innovation that has not been widely publicized and underscores the validity of the initial premise. Users flocked to the site to contact elected officials on what they deemed as important community issues ranging from school funding to the water rates. The implication (and the first lesson from this project) therefore is that innovative tools and services can transform community news, information distribution and visualization, and impact community conversations making new media technology a valued ally to media organizations rather than a disruptive threat.

The second critical lesson from the project is that journalism schools and media organizations ought to partner together to set up innovation incubation centers that can 
help media organizations adapt better to the present challenges. As the New York Times reported recently, there is an emerging trend involving some journalism schools that have decided to establish innovation centers or introduce innovation and entrepreneurship into their curriculum in an attempt to harness the potential of media technologies to meet the modern challenges of journalism (New York Times, 2009). This is a welcome development and could shape the future of media technology. As the Innovation Incubator from Kansas indicated, journalism students are in tune with the present needs in the media world and are equally resourceful. As digital natives and future workers in the media industry, students are untethered to old ways of doing business and may be the change that's needed.

Third, innovation and engagement can come before profit. While the question of money seems to anchor most conversations on innovations in newsrooms, this project proves that a simple and easily executable innovation can indeed bring in engaged audiences who can then be targeted reliably through advertising.

The fourth critical lesson points to the need for media institutions to cast their nets wider in search of salvation and relevance. The creation nets process that was used in this case study is a well-known innovation technique in the business world. But it's not widely used in journalism. Indeed this study could find no other instance where the technique had been used in a journalism setting. This means that since the changes in media technology often come from outside journalism (especially from the field of computer science), there is need for media organizations to step beyond familiar territories in looking for innovation and to consider partnering with non-traditional disciplines. It would be interesting to see what a triangulated collaboration between computer science, journalism and business schools could produce.

Fifth, it is important to have a leadership that supports and encourages a culture of innovation. The Voxpop project was embraced by the management at the Manhattan Mercury for its potential civic value in engaging the local community. Literature reviewed above shows media innovations are largely driven by users instead of the media 
organizations. There is need for a paradigm shift and a change in organizational culture to be able to anticipate trends and respond accordingly. And whether such innovations involve embracing or developing new tools or in making new value propositions, the real asset in a paradigm re-orientation is in creating an organization that is structurally flexible and an organization where change is organic.

Finally, the high use of the Voxpop innovation indicated that well designed innovations could add value to human communication in new ways that impact policy, community organization and conversations. For example, by adding a mapping component to Voxpop, citizens as well as elected leaders could visually associate issues with zip codes, come up with location-specific responses or move in to prevent an issue from becoming widespread. Such value-adding communication technology provides the over-riding lesson from this project-------- that innovation in communication technology that are engaging, need-driven, easy to use and that allow for new ways of using and visualizing information are likely to have a more favorable audience reception and may offer a lifeline for media in the current crises.

\section{References}

Boczkowski, P. (2004) Digitizing the News: Innovation in Online Newspapers. Cambridge, Mass.: MIT Press.

Bratich, J. (2004) Trust no one [On the Internet], Television and New Media, Vol. 5 No. 2.

Brian Stelter (2009) “J-Schools Play Catchup,” New York Times, April 14, 2009, URL (consulted Sept. 2010): http://www.nytimes.com/2009/04/19/education/edlife/journ-t.html,

Campaign (2010) "How technology can herald a new lease of life for print" Campaign March 5, 2010: p.14. London: Haymarket Business Publications

Chesbrough, Henry (2005). Open Innovation: The New Imperative for Creating and Profiting from Technology. Cambridge: Harvard Business Press. 
Christensen, Clayton M. and Bower, Joseph L (1995) "Disruptive Technologies: Catching the Wave" Harvard Business Review, pp 43-53, January-February 1995 Dahlgren, P (1996) "Media Logic in Cyberspace: Repositioning Journalism and its Publics," Javnots/The Public 3:(3): 59-77

Deuze, M. (2003), "The Web and Its Journalisms: Considering the Consequences of Different Types of Newsmedia Online," New Media \& Society 5 (2): 203-230.

Greer, J.D., \& Mensing, D. (2006) "The Evolution of Online Newspapers: A Longitudinal Content Analysis, 1997-2003," in Xigen Li (ed.) Internet Newspapers: The Making of a Mainstream Medium, pp. 13-32. New Jersey: Lawrence Erlbaum.

Hagel, J., Brown, J. (2006) "Creation Nets: Harnessing the Potential of Open Innovation," URL (consulted 2010): http://www.johnhagel.com/creationnets.pdf

Kanter. R.M. (2002) “News Innovation and Leadership,” Nieman Reports 56(2): 30-34.

Lawson-Borders, G. (2003) "Integrating New Media and Old Media: Seven Observations of Convergence as a Strategy for Best Practices in New media Organizations. The International journal on Media Management 5 (2): 91-99.

Nip, Joyce (2006) 'Exploring the Second Phase of Public Journalism," Journalism Studies, 7(2): 212-236

Pew Project for Excellence in Journalism (2010) "The State of the News Media," URL (consulted Oct. 2010): (http://www.stateofthemedia.org/2010/newspapers_summary_essay.php

Rogers, E.M (1964) Diffusion of Technologies. NY: The Free Press.

Rosenberry, J. (2005). "Few Papers Use Online Techniques to Improve Public Communication," Newspaper Research Journal, 26 (4): 61-73.

Sagan, P and Leighton, T (2010) "On The Future of News," Daedalus, Vol. 139 (2): 119-125. Boston: MIT Press.

Shirky, C. (2008). Here comes everybody: The power of organizing without organizations. New York: Penguin Press. 
Schultz, T. (1999) "Interactive Options in online journalism: A content analysis of 100 US newspapers," Journal of Computer Mediated Communication. 5(1) URL (consulted Oct. 2010): http://jcmc.indiana.edu/vol5/issue1/schultz.html

Tremayne, Mark., Amy Schmitz Weiss, and Rosental Calmon Alves (2007). "From Product to Service: The Diffusion of Dynamic Content in Online Newspapers," Journalism \& Mass Communication Quarterly 84 (4): 825-839.

USA Today (2009). "Ways to Rescue "Watchdog” Media," Farmingdale 138, (2775) p 12-14.

Waitley, D., and Tucker, R.(1987) "How to Think Like an Innovator," Futurist 21, no. 2: 9-15:

Westlund, O., (2008). "From Mobile Phone to Mobile Device: News Consumption on the Go," Canadian Journal of Communication. Toronto: 2008, 33, (3): 443-463

Wilkinson, E.J. (2010) News media Outlook 2010: Last Minutes of Danger, Last Minutes of Opportunity. Dallas: INMA.

Zamith, F. (2009). A methodological proposal to analyze the news websites use of the potentialities of the Internet. Paper presented at the 9th International Symposium on Online Journalism, Austin, TX. April, 5, 2009. 